\title{
PATENT DUCTUS ARTERIOSUS WITH PULMONARY HYPERTENSION
}

\author{
BY \\ WILLIAM WHITAKER, DONALD HEATH,* AND JAMES W. BROWN \\ From the Regional Cardicvascular Centre, City General Hospital and the University \\ Department of Medicine, Royal Hospital, Sheffield \\ Received October 12, 1954
}

Several patients with severe pulmonary hypertension associated with patent ductus arteriosus have been described in the past few years by Johnson et al. (1950), Campbell and Hudson (1951), Bothwell et al. (1952), Dammann and Sell (1952), Cosh (1953), Hultgren et al. (1953), and Smith (1954), and these reports suggest that pulmonary hypertension may be a primary abnormality and not secondary to an increased pulmonary blood flow from a shunt through the patent ductus arteriosus. The view, that severe pulmonary hypertension is not a direct complication of patent ductus arteriosus, receives some support from Brown's (1950) observation that cyanosis does not usually occur in the natural history of the lesion, while experience of patients with patent ductus arteriosus associated with severe pulmonary hypertension suggests that it is justifiable to regard this combination as a specific entity, which must be considered in the differential diagnosis of any patient presenting signs of pulmonary hypertension, irrespective of other auscultatory signs or the presence or absence of cyanosis.

The features of eight patients with severe pulmonary hypertension and patent ductus arteriosus are described below and an account of the pathological findings is given in two who died. The clinical manifestations of this combination are defined and its diagnosis by cardiac catheterization and angiocardiography is discussed.

\section{Clinical Features.}

Symptomatology. All eight patients complained of breathlessness on exertion and had frequent coughs and colds. Cases 2 and 5 had a history of hæmoptysis and Case 5 eventually died following a rupture of the pulmonary artery. Four of the five adult patients noted that they were occasionally bluer than normal. Case 2 complained of palpitation.

Signs. From the classical signs of pulmonary hypertension such as a giant " $a$ " wave in the jugular venous pulse, a systolic lift over the right ventricular outflow tract, a palpable second pulmonary sound, and an abnormally loud pulmonary element of the second heart sound on auscultation, it was possible to make a clinical diagnosis of pulmonary hypertension in all eight patients. The other clinical features are shown in Table I.

Electrocardiography. The cardiogram showed right ventricular dominance in all patients and there was also evidence of right bundle branch block in Cases 1 and 6 (Fig. 1 and 2).

Radiological Examination. The postero-anterior teleradiograms of the present group of patients 
are reproduced in Fig. 3 and 4. Right ventricular hypertrophy was present in all of them and the other radiological findings are summarized in Table II.

Angiocardiography was performed in six of the eight cases. Films taken two to three seconds after the injection of the contrast medium showed simultaneous filling of the pulmonary arteries and descending aorta, with no dye in the ascending aorta, in Cases 1, 3, 6, 7, and 8 (Fig. 5). In Case 2, early filling of the ascending aorta and pulmonary arteries from the right ventricle showed

\section{TABLE I}

Features of Eight Patients with Patent Ductus Arteriosus Associated with Severe Pulmonary HYPERTENSION

\begin{tabular}{|c|c|c|c|c|c|c|c|c|c|c|}
\hline Case & Age & Sex & $\begin{array}{l}\text { Systemic } \\
\text { blood } \\
\text { pressure } \\
\text { in arms } \\
(\mathrm{mm} . \mathrm{Hg})\end{array}$ & Cyanosis & $\begin{array}{l}\text { Finger } \\
\text { clubbing }\end{array}$ & $\begin{array}{l}\text { Auscultatory } \\
\text { signs in } \\
\text { pulmonary area }\end{array}$ & $\begin{array}{l}\text { Other } \\
\text { auscultatory } \\
\text { signs }\end{array}$ & $\begin{array}{c}\text { Hb grams } \\
\text { per } \\
100 \mathrm{ml} .\end{array}$ & $\begin{array}{l}\text { Hæma- } \\
\text { tocrit }\end{array}$ & $\begin{array}{l}\text { Associated } \\
\text { lesions }\end{array}$ \\
\hline 1 & 5 & $\mathrm{~F}$ & $170 / 80$ & $\begin{array}{l}\text { Lower } \\
\text { extremities } \\
\text { only }\end{array}$ & Present & $\begin{array}{l}\text { Gibson murmur. } \\
\text { P2 loud and split }\end{array}$ & $\begin{array}{l}\text { Diastolic } \\
\text { murmur and } \\
\text { systolic } \\
\text { murmur at } \\
\text { apex }\end{array}$ & $14 \cdot 4$ & - & $\begin{array}{l}\text { Coarctation } \\
\text { of aorta }\end{array}$ \\
\hline 2 & 26 & $\mathrm{~F}$ & $115 / 75$ & Slight & Present & $\begin{array}{l}\text { No murmur. } \\
\text { P2 loud and split }\end{array}$ & Nil & $18 \cdot 1$ & 58 & $\begin{array}{l}\text { Overriding } \\
\text { aorta }\end{array}$ \\
\hline 3 & 6 & $\mathbf{M}$ & $105 / 35$ & Absent & Absent & $\begin{array}{l}\text { Systolic murmur. } \\
\text { P2 loud and split }\end{array}$ & $\begin{array}{l}\text { Diastolic and } \\
\text { systolic } \\
\text { murmur at } \\
\text { apex }\end{array}$ & $12 \cdot 2$ & 40 & $\begin{array}{l}\text { Ventricular } \\
\text { septal } \\
\text { defect }\end{array}$ \\
\hline 4 & 58 & $\mathrm{~F}$ & $160 / 105$ & Moderate & Absent & $\begin{array}{l}\text { No murmur. } \\
\text { P2 loud and split }\end{array}$ & $\begin{array}{l}\text { Triple rhythm } \\
\text { at lower end of } \\
\text { sternum }\end{array}$ & $25 \cdot 0$ & 77 & Nil \\
\hline 5 & 22 & $\mathrm{~F}$ & $190 / 90$ & Moderate & Present & $\begin{array}{l}\text { Diastolic } \\
\text { murmur. P2 } \\
\text { loud and split }\end{array}$ & $\begin{array}{l}\text { Diastolic } \\
\text { murmur at } \\
\text { apex }\end{array}$ & $20 \cdot 0$ & 71 & $\begin{array}{l}\text { Mitral } \\
\text { stenosis }\end{array}$ \\
\hline 6 & 46 & $F$ & $100 / 60$ & Absent & Absent & $\begin{array}{l}\text { No murmur. } \\
\text { P2 loud and split }\end{array}$ & $\begin{array}{l}\text { Rumbling } \\
\text { diastolic } \\
\text { murmur at } \\
\text { apex }\end{array}$ & $14 \cdot 8$ & 45 & Nil \\
\hline 7 & 8 & F & $90 / ?$ & \begin{tabular}{|l|} 
Lower \\
extremities \\
only
\end{tabular} & Absent & $\begin{array}{l}\text { Systolic and } \\
\text { diastolic } \\
\text { murmurs. } \\
\text { P2 loud }\end{array}$ & Nil & $11 \cdot 1$ & - & Nil \\
\hline 8 & 34 & $F$ & $100 / 70$ & Moderate & Present & $\begin{array}{l}\text { Systolic murmur. } \\
\text { P2 loud and } \\
\text { split }\end{array}$ & Nil & $14 \cdot 5$ & - & Nil \\
\hline
\end{tabular}

that an overriding aorta was present. This patient was, however, shown by cardiac catheterization to have, in addition, a patent ductus arteriosus and the catheter was passed from the pulmonary artery into the descending aorta (Fig. 6).

Cardiac Catheterization. This investigation was carried out in all patients except Cases 4 and 5, and in five of the six, the catheter was passed through the ductus (Fig. 6 and 7). The other findings at cardiac catheterization are summarized in Table IJI. 


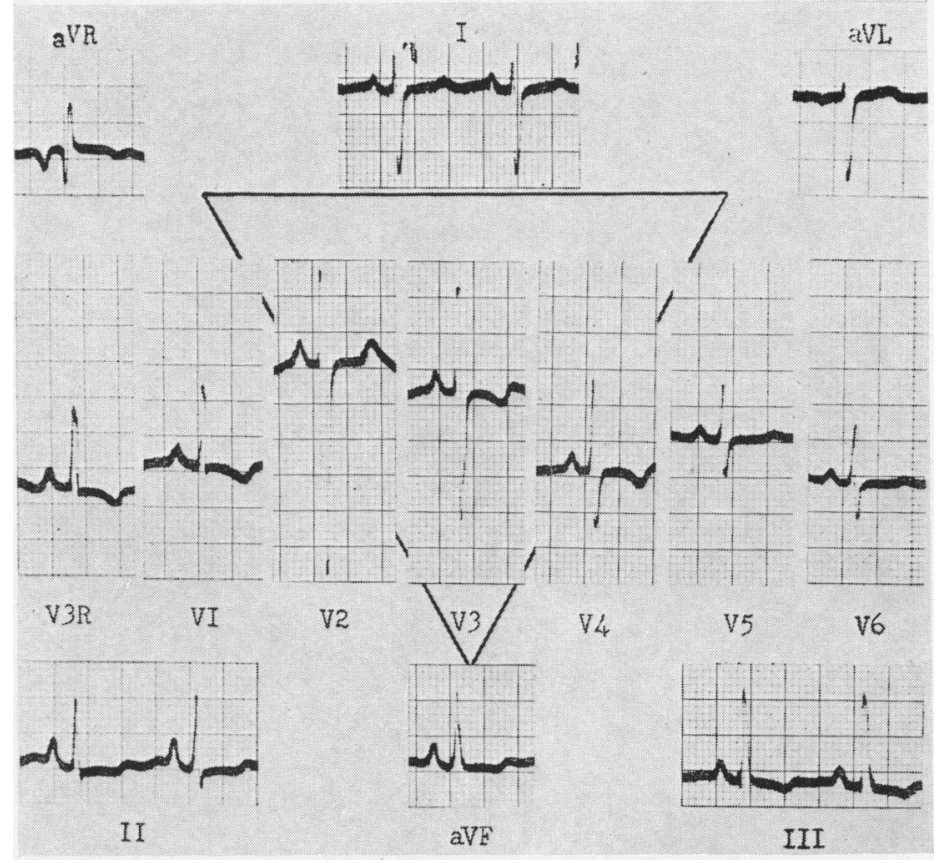

FIG. 1.-Case 2. Electrocardiogram showing pattern of right ventricular hypertrophy and clockwise rotation of a vertical heart.

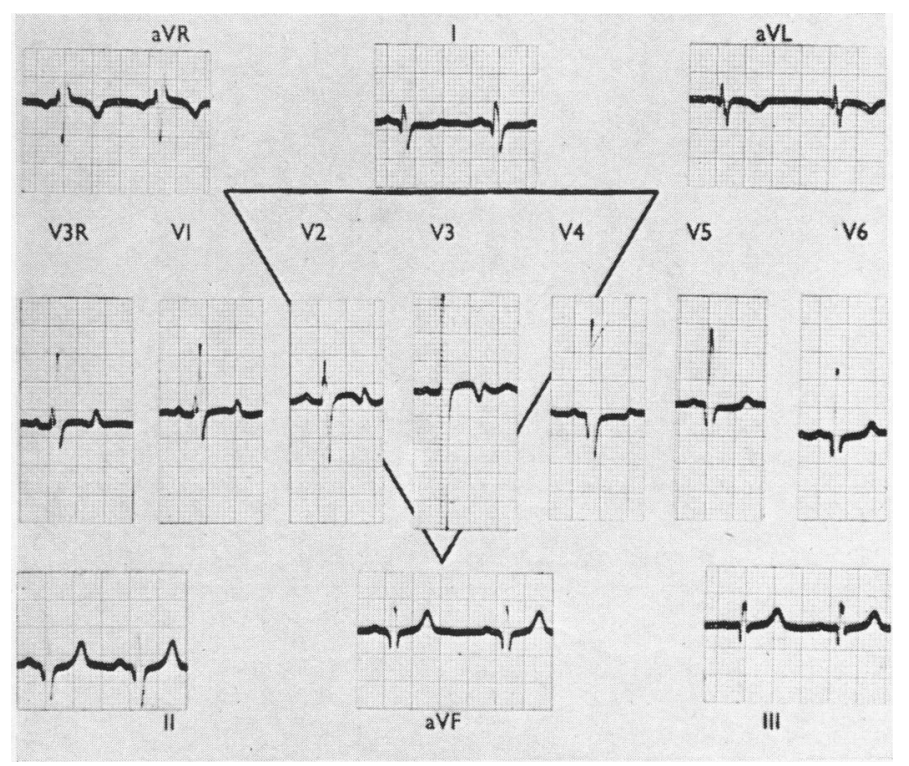

Fig 2.-Case 1. Electrocardiogram showing pattern of incomplete right bundle branch block. 


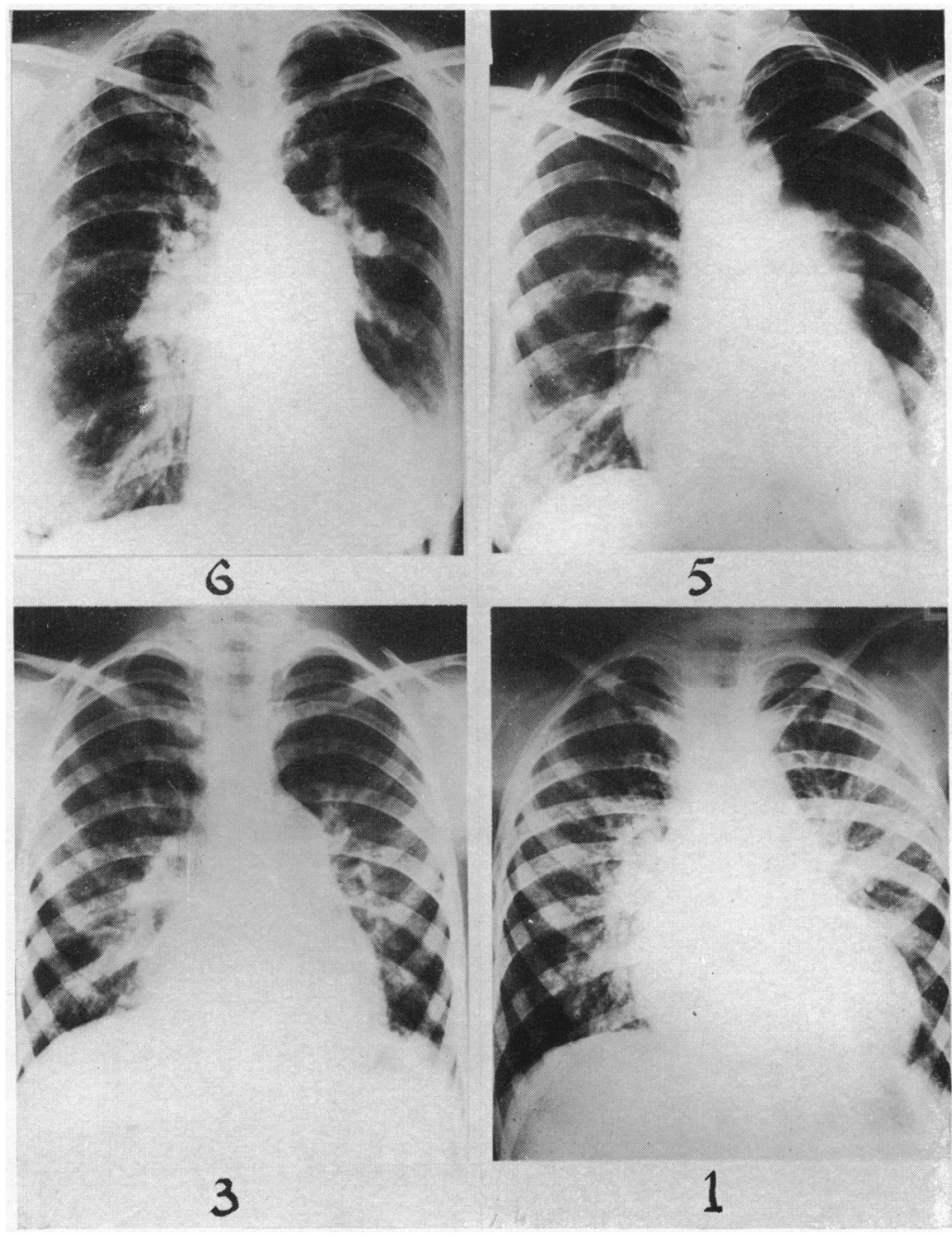

FIG. 3.-Postero-anterior teleradiogram of four patients (Cases 6, 5, 3, and 1) with patent ductus arteriosus and pulmonary hypertension.

TABLE II

Abnormal Radiological Findings in Eight Patients with Patent Ductus Arteriosus and SeVERe Pulmonary HyPertension

\begin{tabular}{c|c|c|c|c}
\hline Case & $\begin{array}{c}\text { Degree of cardiac } \\
\text { enlargement }\end{array}$ & $\begin{array}{c}\text { Prominence of main } \\
\text { pulmonary artery }\end{array}$ & $\begin{array}{c}\text { Abnormal pulsation of } \\
\text { the pulmonary artery }\end{array}$ & $\begin{array}{c}\text { Left atrial } \\
\text { enlargement }\end{array}$ \\
\cline { 1 - 2 } 1 & Marked & Moderate & Present & Present \\
2 & None & Slight & Absent & Absent \\
3 & Moderate & Marked & Present & Absent \\
4 & Slight & Slight & No note & Absent \\
5 & Moderate & Extreme & Present & Absent \\
6 & Slight & Marked & Present & Absent \\
7 & Slight & Slight & Present & Absent \\
8 & Slight & Moderate & Present & Absent \\
\hline
\end{tabular}




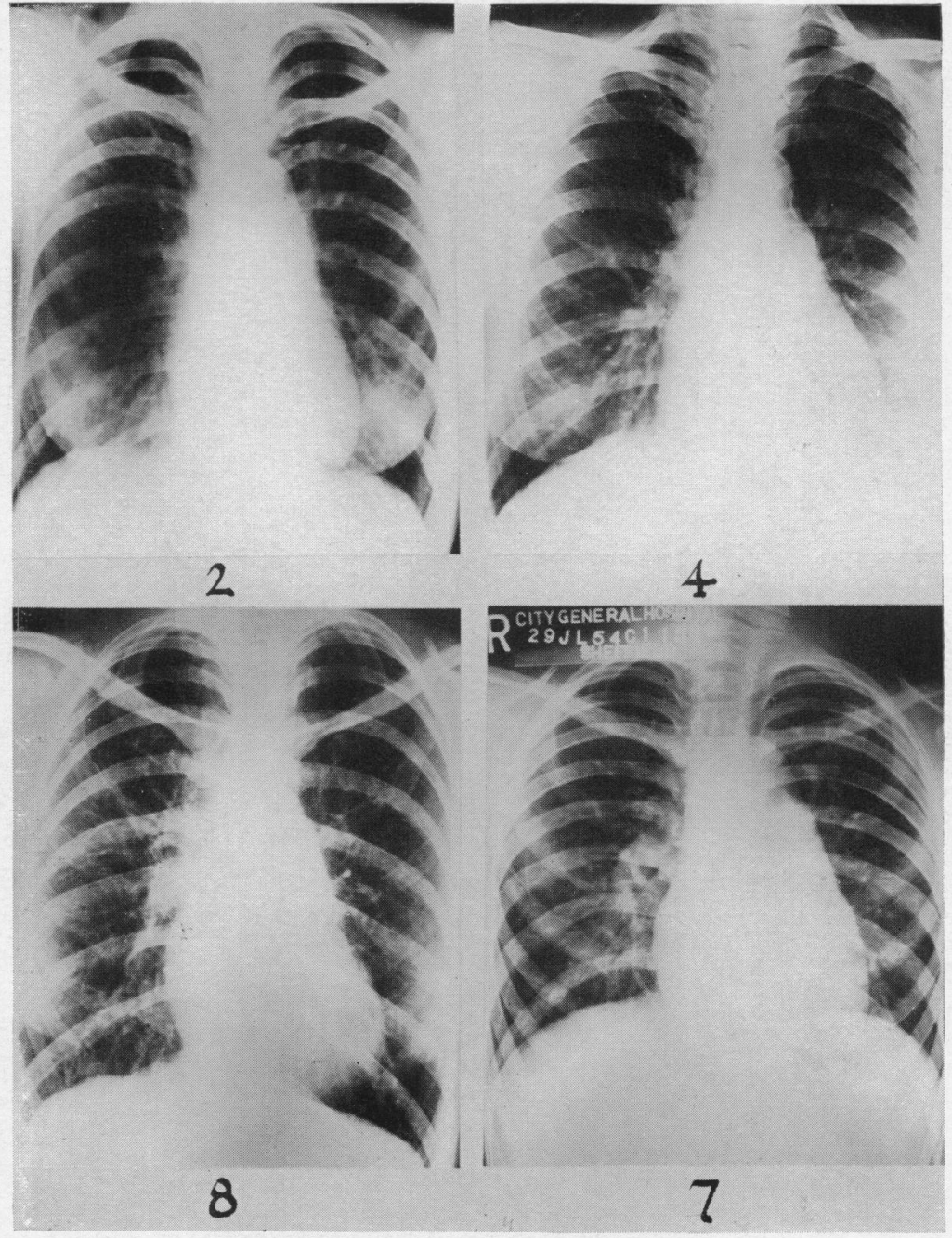

FIG. 4.-Postero-anterior teleradiogram of four patients (Cases 2, 4, 8, and 7) with patent ductus arteriosus and pulmonary hypertension.

\section{AUTOPSY FINDINGS}

Case 4. The heart weighed $460 \mathrm{~g}$. and the right ventricle was dilated and hypertrophied. The wall of the right ventricle was $1.6 \mathrm{~cm}$. thick and that of the left ventricle $1.8 \mathrm{~cm}$. The main pulmonary artery was dilated and the abnormally dilated and thick-walled intrapulmonary arteries stood out more clearly than usual on the cut surface of the lung. The left pulmonary artery was blocked by ante-mortem thrombus and old portions of ante-mortem thrombus were found in its branches, especially those to the lower lobe which was infarcted and showed pleurisy of several days' duration. There was a large patent ductus arteriosus leading from the descending aorta into the pulmonary artery at its bifurcation. This vessel was about $1 \mathrm{~cm}$. long and about $2 \mathrm{~cm}$. in diameter and its site of origin in the descending aorta showed that it was a patent ductus arteriosus rather than an aorto-pulmonary septal defect. There was widespread atheroma of both extrapulmonary and the elastic intrapulmonary arteries (Fig. 8 and 9). There was no evidence of mitral stenosis or a septal defect.

On histological examination the elastic pulmonary arteries $(>1 \mathrm{~mm}$. in diameter) showed gross atheromatous change in the intima. In some of these vessels the atheromatous material was four times the 


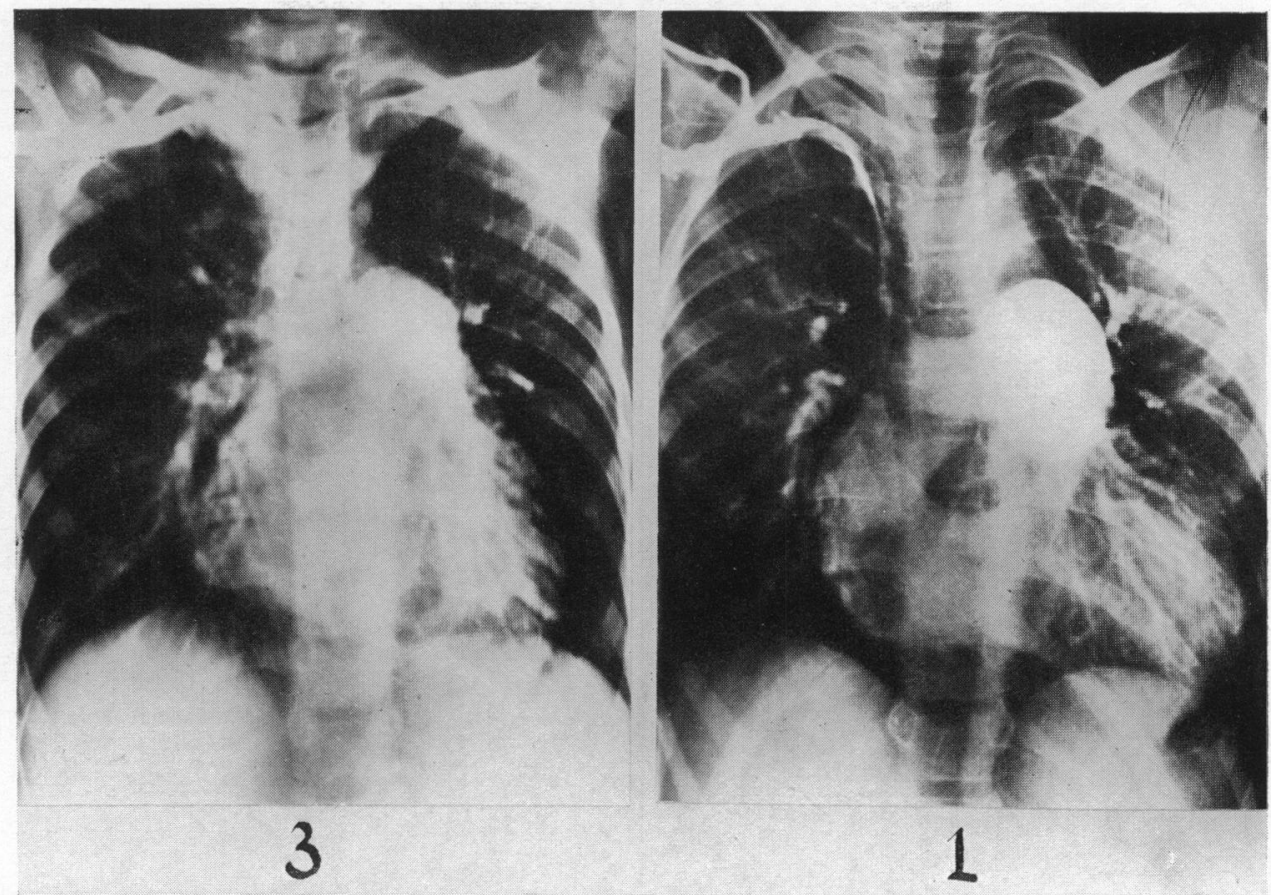

Fig. 5.-Antero-posterior angiocardiograms taken 3 seconds after the injection of the contrast medium in Cases 1 and 3, showing simultaneous filling of the pulmonary arteries and the descending aorta.
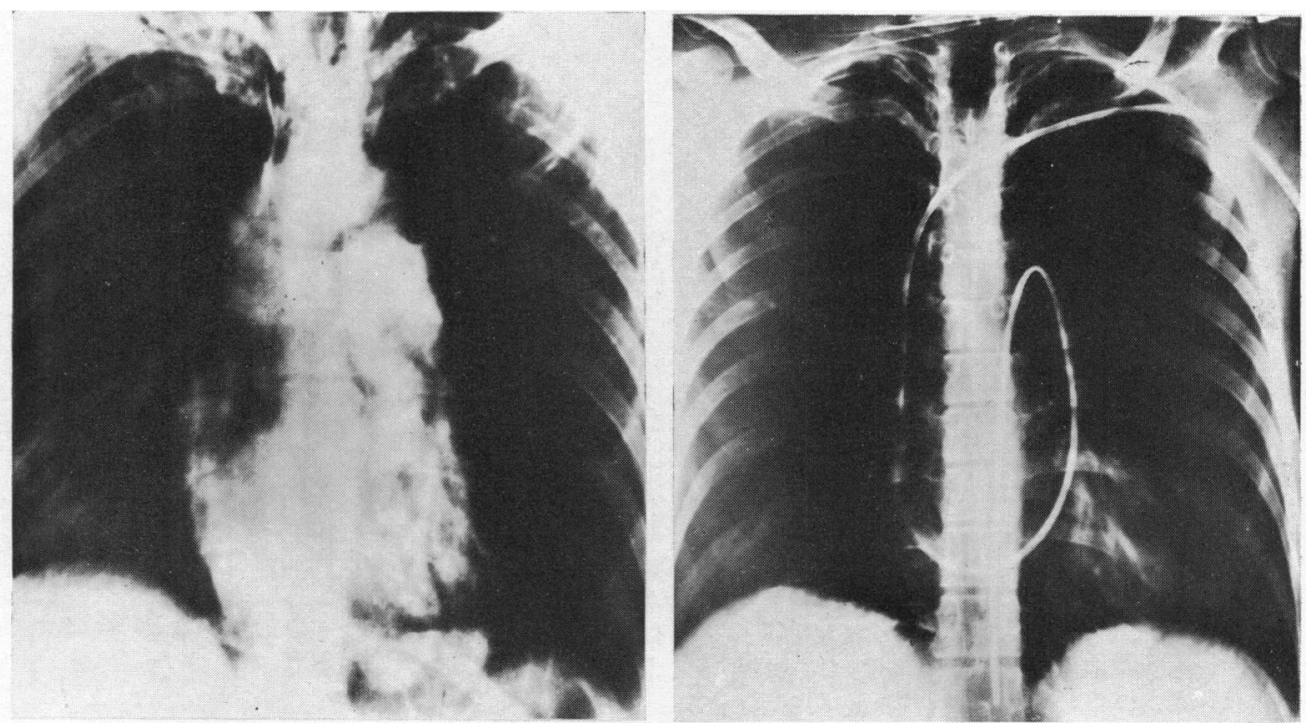

Fig. 6.-Case 2. The antero-posterior angiocardiogram, reproduced on the left, shows simultaneous filling of the pulmonary arteries and the ascending aorta from the right ventricle 3 seconds after the injection of the contrast medium. The film on the right shows a cardiac catheter passing from the pulmonary artery through a patent ductus arteriosus into the descending aorta in the same patient. 


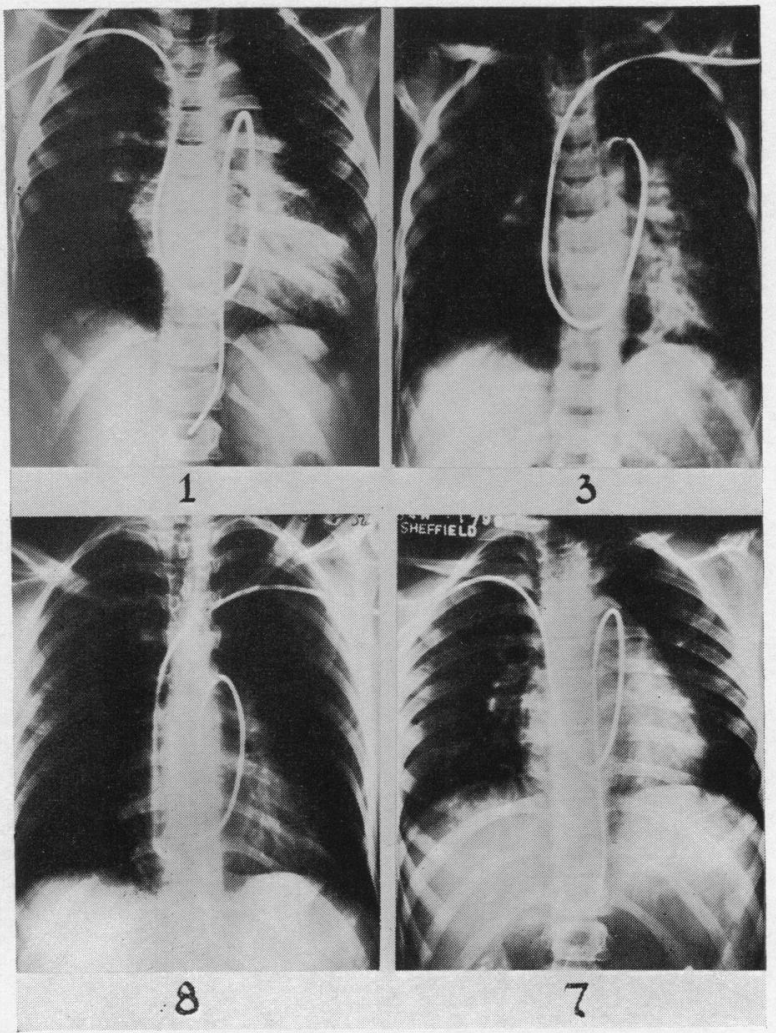

Fig. 7.-Films taken at cardiac catheterization in Cases 1, 3, 7 , and 8 , showing the cardiac catheter passing from the pulmonary artery through the patent ductus into the descending aorta. In Case 3 the descending aorta has been outlined by the injection of contrast medium through the catheter.

TABLE III

Results of Cardiac Catheterization in Six Patients with Patent Ductus Arteriosus and SeVere Pulmonary HyPertension

\begin{tabular}{|c|c|c|c|c|c|c|c|c|}
\hline \multirow[b]{2}{*}{ Case } & \multicolumn{6}{|c|}{ Blood oxygen saturation, percentages } & \multirow{2}{*}{$\begin{array}{l}\text { Pulmonary } \\
\text { artery blood } \\
\text { pressure } \\
(\mathrm{mm} . \mathrm{Hg})\end{array}$} & \multirow{2}{*}{$\begin{array}{c}\text { Aortic blood } \\
\text { pressure } \\
(\mathrm{mm} . \mathrm{Hg})\end{array}$} \\
\hline & $\begin{array}{c}\text { Femoral } \\
\text { artery }\end{array}$ & $\begin{array}{c}\text { Inferior } \\
\text { vena cava }\end{array}$ & $\begin{array}{l}\text { Superior } \\
\text { vena cava }\end{array}$ & $\begin{array}{l}\text { Right } \\
\text { auricle }\end{array}$ & $\begin{array}{c}\text { Right } \\
\text { ventricle }\end{array}$ & $\begin{array}{l}\text { Pulmonary } \\
\text { artery }\end{array}$ & & \\
\hline $\begin{array}{l}1 \\
2 \\
3\end{array}$ & \multirow{2}{*}{$\begin{array}{c}97 \\
86 \\
\text { Aortic } 98 \\
* 83 \\
97 \\
92 \\
80\end{array}$} & $\begin{array}{l}-71 \\
67\end{array}$ & $\begin{array}{l}\overline{70} \\
69\end{array}$ & $\begin{array}{l}77 \\
71 \\
69\end{array}$ & \multirow{2}{*}{$\begin{array}{c}78 \\
71 \\
\text { Low } 74 \\
\text { High } 83 \\
77 \\
65 \\
55\end{array}$} & $\begin{array}{l}78 \\
75 \\
86\end{array}$ & $\begin{array}{l}120 / 100 \\
125 / 75 \\
105 / 60\end{array}$ & $\begin{array}{l}105 / 95 \\
130 / 75 \\
115 / 70\end{array}$ \\
\hline $\begin{array}{l}6 \\
7 \\
8\end{array}$ & & $\begin{array}{l}85 \\
70 \\
54\end{array}$ & $\begin{array}{l}71 \\
72 \\
53\end{array}$ & $\begin{array}{l}79 \\
62 \\
53\end{array}$ & & $\begin{array}{l}87 \\
67 \\
63\end{array}$ & $\begin{array}{l}100 / 55 \\
120 / 80\end{array}$ & $\begin{array}{c}\text { Not recorded } \\
110 / 70\end{array}$ \\
\hline
\end{tabular}

* While under general anæsthesia for angiocardiogram. 


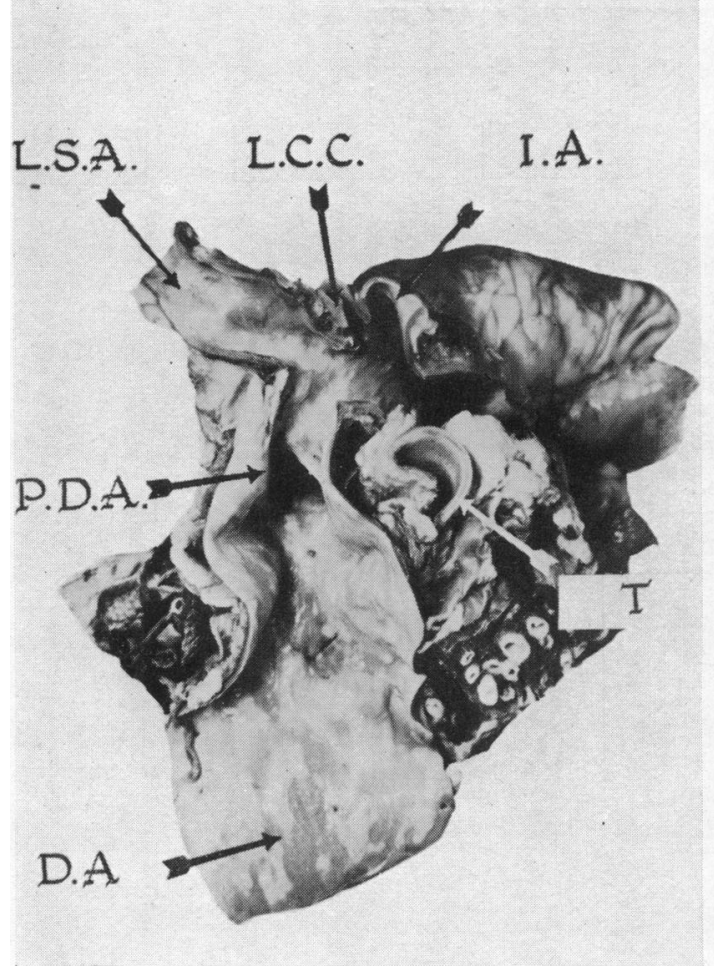

FIG. 8.-The aorta has been opened from behind to show the opening of the large patent ductus arteriosus beyond the origin of the left subclavian artery. The hypertrophied pulmonary vessels are obvious in the cut section of the lung. The aorta shows atheromatous change. Case 4.

$\mathrm{T}=$ Trachea. $\quad \mathrm{DA}=$ Descending Aorta. $\mathrm{PDA}=$ Patent Ductus Arteriosus. LSA $=$ Left Subclavian Artery. LCC $=$ Left Common Carotid Artery. $\mathrm{IA}=$ Innominate Artery.

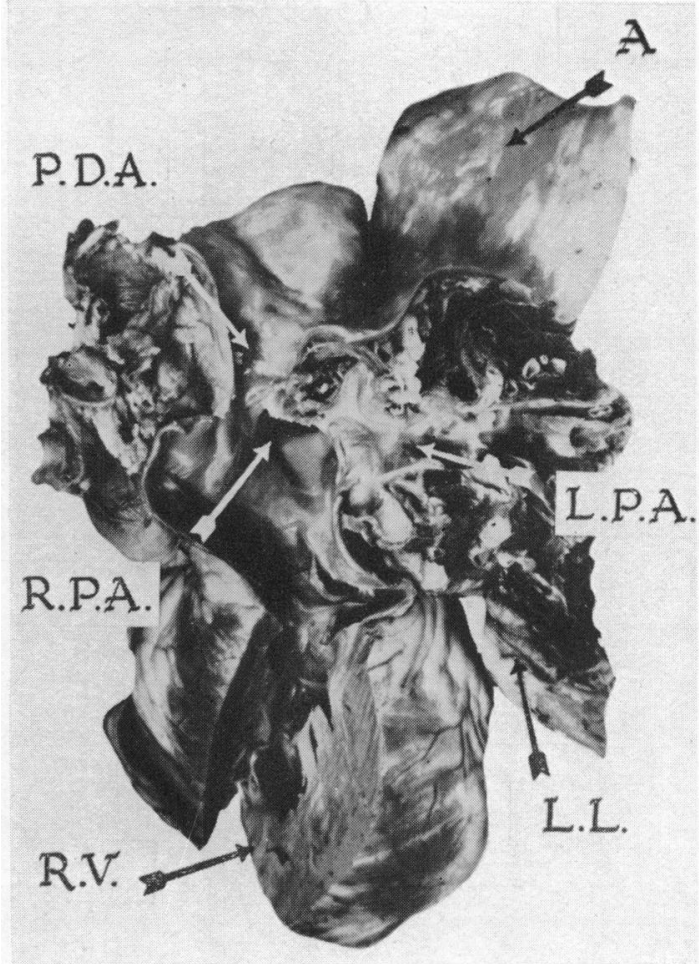

FIG. 9.- The heart and great vessels have been dissected to show the patent ductus arteriosus passing from the bifurcation of the pulmonary artery into the descending aorta. The right ventricle is hypertrophied and there is atheroma in the patent ductus and the aorta. Case 4.

$A=$ Aorta. $\quad$ PDA = Patent Ductus Arteriosus. LPA $=$ Left Pulmonary Artery. RPA $=$ Right Pulmonary Artery. $\quad L L=$ Left Lung. $\quad R V=$ Right Ventricle.

thickness of the media. At the junction of the media and intima the elastic fibres were ruptured in many places, but the more peripheral fibres were normal. The adventitia was normal (Fig. 10).

The muscular arteries $(0 \cdot 1-1 \mathrm{~mm}$. in diameter) showed a proliferation of fibro-elastic tissue in the intima. The lumen of most of the vessels was narrowed, while in others it was completely blocked; recanalization had occurred in some vessels. The media of the small muscular arteries was hypertrophied. Both elastic membranes were well defined and, although the internal elastic membrane was thicker than normal, it was not split. The adventitia was normal (Fig. 11). The arterioles $(<0 \cdot 1 \mathrm{~mm}$. in diameter) showed the same changes in the intima and media as the muscular arteries and many of these vessels were completely blocked. In some, the proliferated intimal tissue had completely disorganized the structure of the vessels (Fig. 12). The pulmonary veins were normal and there was no evidence of thrombosis in the small veins.

Case 5. There was a hæmopericardium from a rupture of a dissecting aneurysm of the pulmonary artery and $520 \mathrm{ml}$. of blood clot were present in the pericardial cavity. The heart was enlarged and weighed $520 \mathrm{~g}$. The right ventricle was dilated and hypertrophied and its wall was $1.5 \mathrm{~cm}$. thick. The main pulmonary artery was dilated. The pulmonary artery and aorta were both very friable and the aorta was two-thirds the average diameter for a person of this height and weight. The aorta was collapsed like a flat ribbon and tore like wet blotting paper. There was a hæmatoma in the wall of the pulmonary artery above the pulmonary valve and bleeding from this had given rise to the hæmopericardium. The blood had spread between the media and adventitia. The dissected wall extended $5 \mathrm{~cm}$. above the valve and the site of rupture was $1.5 \mathrm{~cm}$. above the valve on the anterior surface. The length of the rupture was $0.8 \mathrm{~cm}$. There was an 


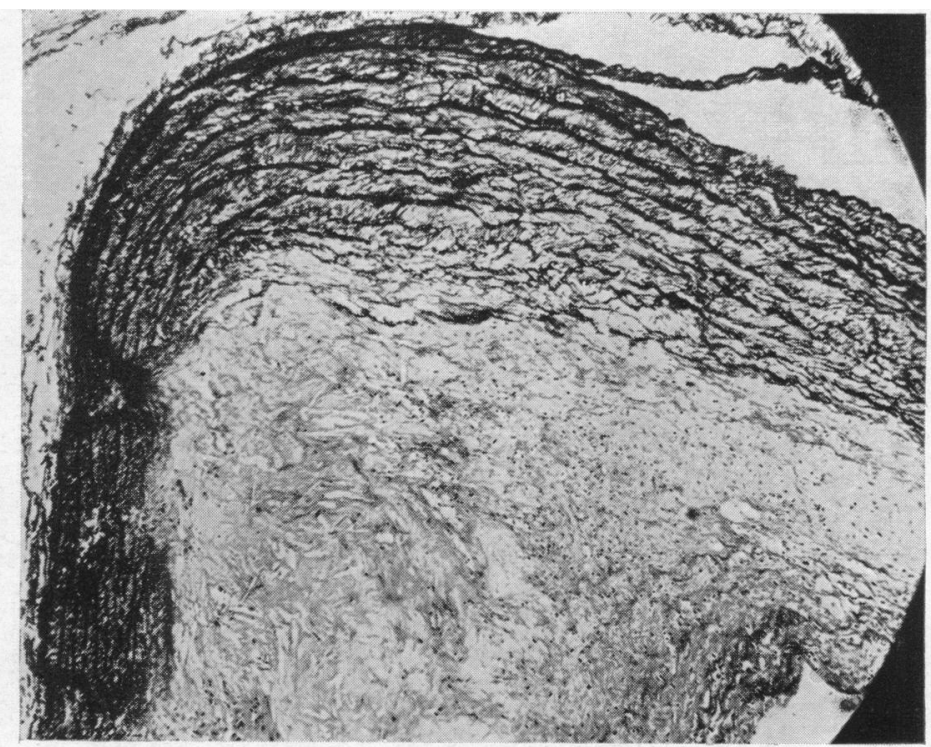

FIG. 10.--Transverse section of elastic pulmonary artery, showing gross atheromatous change in the intima. The elastic fibres are ruptured in many places at the junction of media and intima. Veerhoff/Van Gieson, $\times 52$. Case 4 .

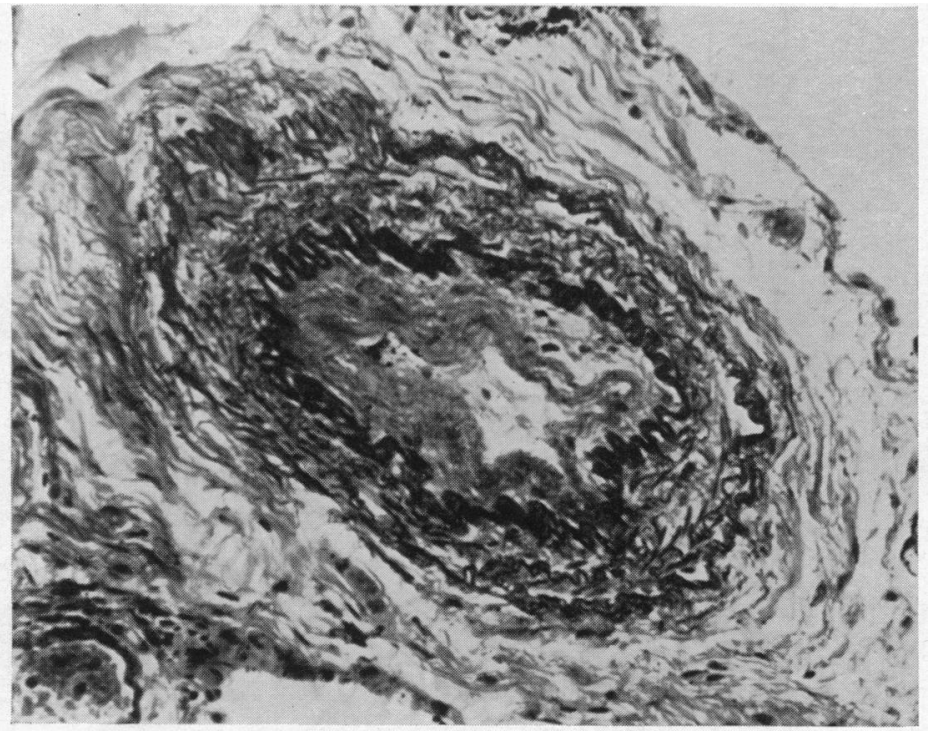

FIG. 11.- Transverse section of muscular pulmonary artery. There is proliferation of fibroelastic tissue in the intima. The media is hypertrophied and both elastic laminæ are thick. Veerhoff/Van Gieson, $\times 200$. Case 4 . 


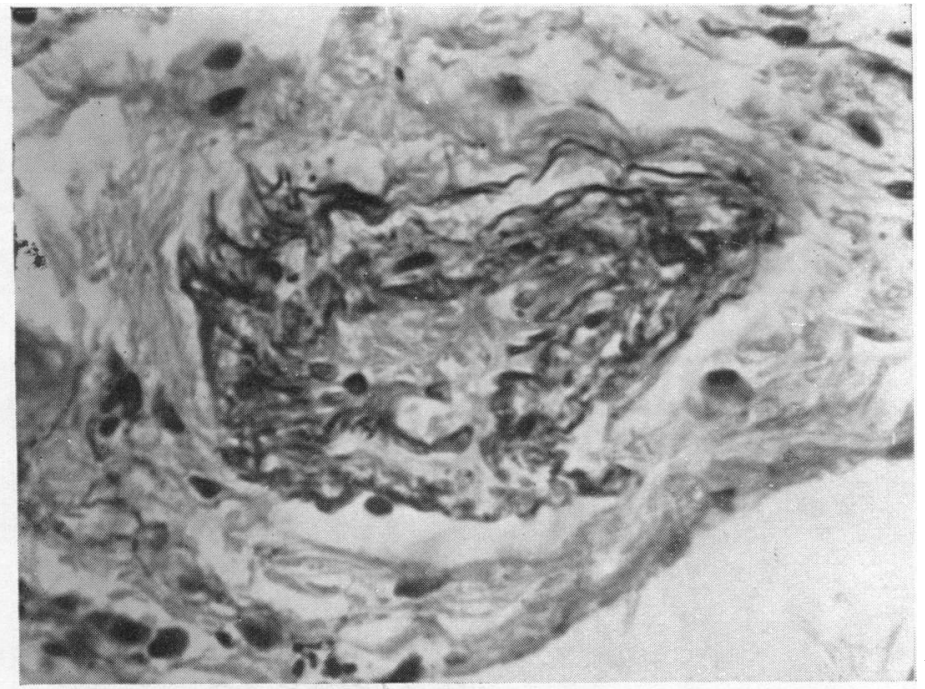

FIG. 12.-Transverse section of pulmonary arteriole. There is proliferation of intimal fibrous tissue, obliterating the lumen. The media is hypertrophied. Veerhoff/Van Gieson, $\times 530$. Case 4.

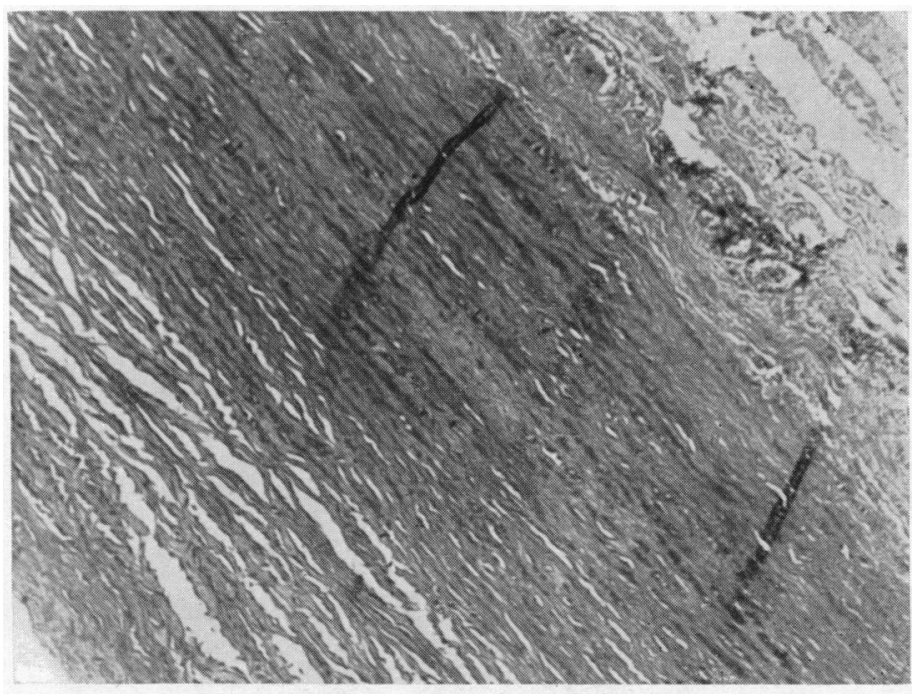

FIG. 13.-Part of transverse section of main pulmonary artery, showing areas of medionecrosis. Case 5.

abnormal communication, of no appreciable length, $1.5 \mathrm{~cm}$. in diameter, which opened into the aorta $2 \mathrm{~cm}$. below the lumen of the left subclavian artery (Fig. 14) and into the left pulmonary artery at its origin $4.5 \mathrm{~cm}$. above the pulmonary cusps. The site of the opening of this abnormal communication into the aorta suggested it was a patent ductus arteriosus rather than an aorto-pulmonary septal defect. There was an isolated plaque of atheroma in the ductus itself but the rest of the pulmonary arteries were free. A narrowed mitral ring admitted the tip of one finger with difficulty. The tricuspid valve admitted only two fingers. There was no evidence of a septal defect. The aortic valve had two cusps and there was thickening and slight calcification at the expected site of the missing commissure of the fused cusp. The papillary muscles 


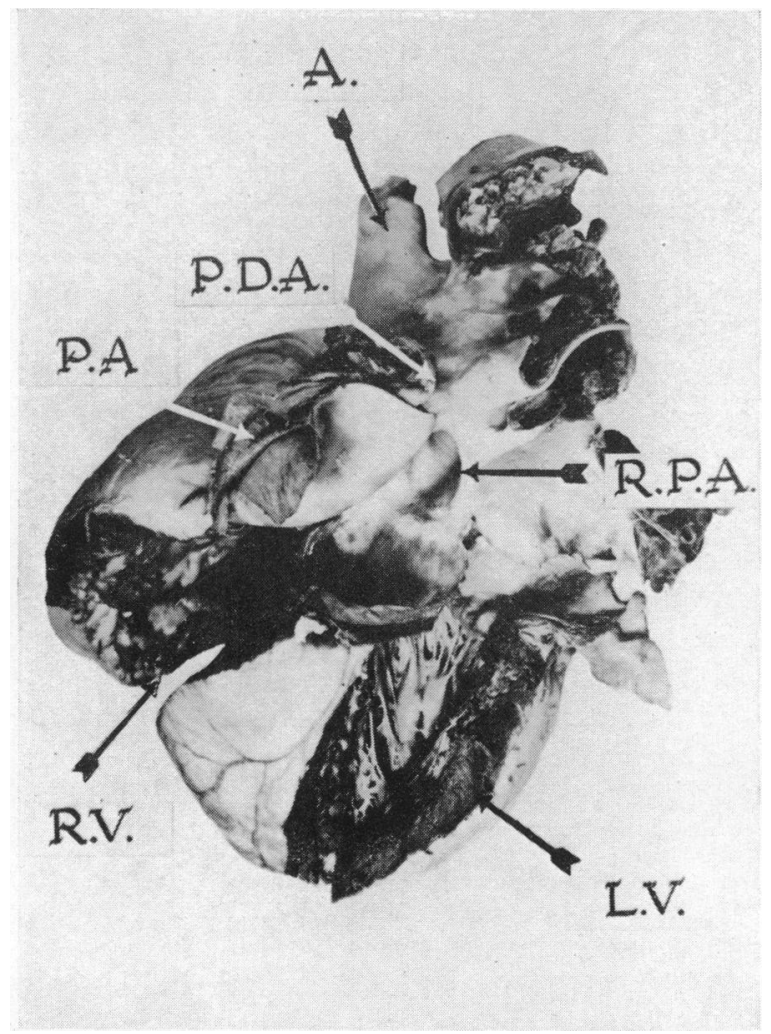

FIG. 14.-The heart and great vessels, showing a window-like patent ductus arteriosus, which has been opened, passing from the origin of the left pulmonary artery into the descending aorta. The wall of the main pulmonary artery is split and this contained blood clot. The right ventricle is thicker than the left. The aorta is free from atheroma. Case 5.

$\mathrm{A}=$ Aorta. $\quad \mathrm{PDA}=$ Patent Ductus Arteriosus. $\mathrm{RPA}=$ Right Pulmonary Artery. PA $=$ Pulmonary Artery. LV=Left Ventricle. $R V=$ Right Ventricle.

in the right ventricle were twice as thick as in the left. The coronary arteries were normal. The main pulmonary artery and aorta on histological examination showed the changes of medio-necrosis. There were bluish hyaline streaks which stained metachromatically as pseudo-mucin and, in addition, some elastic fibres stained irregularly (Fig. 13). These changes were extensive in the media of the main arteries. The muscular arteries showed similar histological changes to those described in Case 4, but these were much less severe and less widespread.

\section{Discussion}

Symptomatology. Symptoms that have been reported in patients with patent ductus arteriosus and severe pulmonary hypertension are breathlessness on exertion, frequent chest infections, hæmoptysis, substernal pain, and cyanosis, and those of the present series are similar. Breathlessness on exertion which occurred in all the previously reported cases (Johnson et al, 1950; Campbell and Hudson, 1951; Bothwell et al, 1952; Dammann and Sell, 1952; Cosh, 1953; Hultgren et al., 1953; Smith, 1954), was a symptom of all patients in the present series. Dammann and Sell (1952), found that recurrent attacks of pneumonia were common in their patients and, although none of the present patients gave a history of pneumonia, seven of them suffered from recurrent attacks of 
pulmonary infection and the other had chronic asthma. Two of our cases had hæmoptysis and this also occurred in patients reported by Campbell and Hudson (1951) and Johnson et al. (1950). Hultgren et al. (1953) noted attacks of substernal pain on exertion in three of their eight patients while Smith's (1954) patient complained of a tightness over the præcordium on exertion. None of the present patients had chest pain but the one with asthma had tightness in the chest. In four of the five adults in the present series and in the patient reported by Campbell and Hudson (1951), cyanosis was so marked as to be discernable by them. The symptoms described above occurred with such frequency in patients with this anomaly as to be considered characteristic of it, but they are not pathognomonic of it since similar symptoms are a feature of other congenital defects such as atrial septal defect, ventricular septal defect, anomalous pulmonary venous drainage or Eisenmenger's complex, and are probably due to pulmonary hypertension associated with these lesions.

Signs. The striking feature of this group of patients, on clinical examination, was pulmonary hypertension which was recognized in all cases by its classical signs. Although previous authors have noted the loud split second pulmonary sound (Campbell and Hudson, 1951; Cosh, 1953; Hultgren et al., 1953; and Smith, 1954), and Bothwell et al. (1952) have described a "forceful epigastric pulsation," they have not mentioned other signs of pulmonary hypertension and it has not been emphasized that these signs are an essential feature of the present anomaly. In any patient with such clinical signs a diagnosis of patent ductus arteriosus and pulmonary hypertension should always be considered in the differential diagnosis.

Five of the eight patients in the present series had abnormally high pulse pressures. This was also a feature of some patients described by Dammann and Sell (1952) but they considered the pulse pressure of little diagnostic aid, since they also observed abnormally high pulse pressures in many of their patients with ventricular septal defects while a normal pulse pressure occurred in one of their patients with a patent ductus arteriosus.

The intensity and distribution of cyanosis with this congenital lesion depends upon the degree of reversal of the shunt. Generalized cyanosis occurs when there is a marked right-to-left shunt causing arterial blood oxygen unsaturation and subsequent polycythæmia. Such generalized cyanosis was present in the case of Campbell and Hudson (1951), in the first patient of Cosh (1953) and in Cases 2, 4, 5, and 8 in the present series, who were also polycythæmic. Case 4 was, in fact, admitted to hospital with a diagnosis of polycythæmia rubra vera. Cyanosis was restricted to the lower extremities in Cases 1 and 7 and was more obvious after exercise. Cosh (1953) reported this distribution of cyanosis in his second case. There was no cyanosis in Cases 3 and 6 of the present series, nor in Cosh's (1953) third case. Although cyanosis restricted to the lower extremities is usually regarded as a sign of coarctation of the aorta associated with patent ductus arteriosus, it is more correctly a sign of pulmonary hypertension associated with patent ductus arteriosus. This sign occurs in patients with the latter combination in the absence of coarctation of the aorta, while it does not occur in patients with coarctation of the aorta and patent ductus arteriosus unless there is also pulmonary hypertension sufficient to produce a flow of unsaturated blood from pulmonary artery to aorta. Although it is apparent that cyanosis may or may not be associated with the present anomaly it is of the greatest importance as a diagnostic sign when restricted to the lower extremities.

The murmurs noted at the base of the heart in the present group of patients are in accord with those reported by previous observers. Two of our patients had a basal systolic murmur, one a basal systolic murmur and a diastolic murmur, one a basal diastolic murmur only, one a Gibson murmur, and three had no murmurs. A Gibson murmur is an uncommon feature of patent ductus arteriosus when there is associated pulmonary hypertension and in the present series such a murmur was heard only in Case 1, who had also coarctation of the aorta. These unusual auscultatory findings are a manifestation of an abnormal blood flow through the patent ductus arteriosus. Only a basal systolic murmur was present in fifteen patients reported by Dammann and Sell (1952) and these observers suggested that this was due to the flow through the ductus occurring only in systole. Johnson et al. (1950) and Campbell and Hudson (1951) noted that the dominant basal murmur 
was in diastole and these latter observers thought that it was probably the murmur of pulmonary incompetence. Since murmurs were absent in three of our patients where there was still evidence of blood flow through the patent ductus arteriosus, from cyanosis in the systemic circulation, it was thought that the large size of the patent ductus arteriosus accounted for the absence of murmurs. With the exception of a Gibson murmur, which is rare, basal murmurs are of little diagnostic importance in this anomaly since it may present only a systolic murmur, only a diastolic murmur, a systolic murmur and diastolic murmur, or, indeed, no murmurs. Four of our patients had mitral diastolic murmurs and Dammann and Sell (1952) noted this murmur in 10 of their 15 patients. Since one of our four patients with a mitral diastolic murmur had, at autopsy, organic mitral stenosis, it seems possible that such a mitral diastolic murmur may be a sign of associated mitral stenosis.

The electrocardiogram provides confirmatory evidence of right ventricular hypertrophy which is a diagnostic feature of the anomaly. All eight patients in the present series had striking evidence of right ventricular hypertrophy (Fig. 1 and 2) and this has been noted in most previously reported series.

On radiological examination, all the patients in the present series have shown evidence of cardiac enlargement, particularly of the right side, and increased prominence of the pulmonary artery and its main branches (Table II and Fig. 3 and 4). In six of the eight patients there was increased pulsation of the pulmonary arteries but in none did this amount to a hilar dance. These signs, which are in keeping with those described by the authors quoted previously, are characteristic of, but not diagnostic of, the present anomaly. Patients with the classical features of an atrial septal defect, ventricular septal defect, and mitral stenosis with severe pulmonary hypertension will probably not be confused with the anomaly under discussion on radiological examination, but in less characteristic cases with these lesions and in patients with Eisenmenger's complex, the radiological appearances may be identical with those found with a patent ductus arteriosus and pulmonary hypertension. Patients with an atrial septal defect usually have a more marked pulsation in the pulmonary arteries amounting to hilar dance and greater cardiac enlargement. A ventricular septal defect usually causes more marked left ventricular hypertrophy than has been observed in patients in this series. The degree of left atrial enlargement will usually allow patients with mitral stenosis and pulmonary hypertension to be differentiated from the present anomaly, but this is sometimes impossible since mitral stenosis may occur in association with patent ductus arteriosus and pulmonary hypertension. It also appears probable that many patients diagnosed on clinical and radiological examination as cases of idiopathic pulmonary hypertension are, in fact, examples of the present anomaly or of other congenital septal defects, complicated by pulmonary hypertension.

Angiocardiography will provide confirmatory evidence of a patent ductus arteriosus when the pulmonary blood pressures are sufficiently high to cause the blood to flow from the pulmonary artery to the aorta. Films taken two to three seconds after the injection show contrast medium passing from the right ventricle to the pulmonary arteries and thence into the descending aorta. In the present series, with the exception of Case 2, there was no difficulty in recognizing the source of the contrast medium in the descending aorta since there was no filling of the ascending portion (Fig. 5). In Case 2 there was early filling of the ascending aorta and this patient was considered to have an overriding aorta as well as a patent ductus arteriosus since such marked filling appeared incompatible with regurgitation of the dye into the ascending aorta (Fig. 6). Angiocardiography may be of value even in patients who are not cyanosed for, although the blood flow in such cases is not predominantly from pulmonary artery to aorta, there may be sufficient mixing of the blood for some of the dye to pass from the pulmonary arteries into the aorta as in Case 6.

Cardiac catheterization usually provides confirmatory evidence of a patent ductus arteriosus when associated with pulmonary hypertension. In all cases it demonstrates the pulmonary hypertension and in five of the six patients so investigated in this series the cardiac catheter passed through the ductus into the descending aorta. The ease with which the ductus was catheterized in this series and the frequency with which this has been reported in the series of Cosh (1953), Dammann and Sell (1952) and the case of Smith (1954) show this manœuvre to be a most valuable sign of the present anomaly. The ease of catheterization of the ductus is probably explained by its 
large size and by a predominant blood flow from pulmonary artery to descending aorta. It is of interest to note that the only patient in the present series where the ductus was not catheterized was not cyanosed, and blood samples showed that the shunt was predominantly from aorta to pulmonary artery. It is obvious from the present series (Table I) and other reported cases that a patent ductus arteriosus with pulmonary hypertension may be associated with other anomalies, such as an overriding aorta, a ventricular septal defect, or mitral stenosis, which alone would be sufficient to produce pulmonary hypertension and intubation of the ductus may be the only proof of its existence. If the patent ductus arteriosus had not been catheterized, the diagnosis would have been one of ventricular septal defect alone in Case 3 and one of Eisenmenger's complex alone in Case 2. Examination of the oxygen saturation of blood samples helps in diagnosis. When the shunt is not completely reversed it is possible to recognize the patent ductus from the higher blood oxygen saturation in the pulmonary arteries than in the right ventricle, as in Case 6 . When the shunt is reversed, arterial blood from the lower extremities is less saturated with oxygen than blood from the upper extremities but, although other authors have described this, it was not used as a diagnostic sign in any of our patients. When there are associated lesions such as an atrial or a ventricular septal defect they may be recognized from characteristic changes in the oxygen saturation of blood samples obtained at cardiac catheterization. When such anomalies occur it may be impossible to diagnose a patent ductus arteriosus from the blood samples. In Case 3, the blood oxygen saturations demonstrated a ventricular septal defect and a patent ductus arteriosus was only diagnosed because a catheter was passed through the ductus.

\section{Discussion of Pathology}

Certain pathological features appear to be characteristic of patent ductus arteriosus associated with pulmonary hypertension but since similar changes occur in other forms of congenital heart disease with a high pulmonary artery blood pressure such as Eisenmenger's complex, they cannot be considered pathognomonic of the present anomaly. Such features as right ventricular hypertrophy, dilatation of the main pulmonary artery, and prominence of the intrapulmonary vessels in cut section of the lung, which were present in both our autopsied cases and have been reported by Dammann and Sell (1952), and Hultgren et al. (1953), appear to be intimately related to pulmonary hypertension.

There was a large patent ductus arteriosus in both our cases examined at necropsy and this appears to be characteristic of a ductus associated with pulmonary hypertension since it has been noted previously by Johnson et al. (1950) and Dammann and Sell (1952). In Case 4 in our series there was widespread atheroma in the aorta and throughout the pulmonary arterial tree and in the ductus itself, while in Case 5, there was only an isolated plaque in the ductus. The marked difference in distribution of atheroma, observed in our two patients, is compatible with previous reports. Johnson et al. (1950) found it to be widespread throughout the pulmonary arterial tree, tending to occur especially at certain sites as " impingement plaques," while Dammann and Sell (1952) found that atheroma may be absent.

Johnson et al. (1950) described medial changes in the pulmonary vessels as well as atheroma and stated that in these vessels there was " athero-sclerosis with large numbers of cholesterol-laden macrophages in the intima " and "fraying out and rupture of the elastic tissue of the media at focal points along the wall with aneurysm-like bulging of the intima at such points." In Case 5 of the present series, the walls of the pulmonary artery and aorta were involved by medio-necrosis, although not by atheroma (Fig. 13).

Old pulmonary arterial thrombosis which occurred in the left pulmonary artery and its branches in Case 4 is a complication that has been noted previously by Hultgren et al. (1953) and Smith (1954). This complication has not been a feature of all patients examined at autopsy since it was not present in Case 5 of this series and was not mentioned by Johnson et al. (1950) and Dammann and Sell (1952). Hultgren et al. (1953), in their description, stated that there were recent thrombi 
showing early organization and others that were old showing recanalization. Smith (1954) thought that it was difficult to explain the ætiology of embolism leading to thrombosis in the pulmonary arteries as he found no evidence of endocarditis, endarteritis, or polycythæmia to account for it. Our patient with this complication was extremely polycythæmic.

The histological appearances described above in Case 4 are similar to those reported by previous authors. Dammann and Sell (1952) described medial thickening and severe intimal proliferation. Cosh (1953) found an increase in the muscle and elastic tissue in the media with occasional small raised plaques of fibro-elastic tissue in the intima of the arteries and medial hypertrophy and thickening of the intima in the arterioles. Campbell and Hudson (1951) noted hypertrophy of the adventitia and media with thickening of the intima. Johnson et al. (1950) described intimal proliferation and medial hypertrophy. The causes of these histological changes have been discussed by Hultgren et al. (1953). These latter observers believe that the vascular narrowing was not a direct complication of the patent ductus arteriosus and not due to prolonged increase in the total pulmonary blood flow, since they failed to find pulmonary vascular sclerosis in uncomplicated cases of patent ductus arteriosus and noted that aged patients with patent ductus arteriosus were free from pulmonary arterial lesions. Although they noted that it was possible in animals to produce an acute arteritis and thrombosis by injection of various substances and to produce a high pulmonary artery blood pressure by this means, they do not believe that pulmonary hypertension in the present anomaly followed pulmonary embolism since there was no clinical history of such an event. They accept the theory of Edwards (1953) who believes that pulmonary hypertension is due to persistence of the fœtal state of the pulmonary vasculature so that the final histological appearances are those of infantile pulmonary vessels with superadded changes resulting from the pulmonary hypertension.

\section{DifFERENTIAL Diagnosis}

The differential diagnosis of the present anomaly is from other cyanotic and acyanotic conditions associated with pulmonary hypertension. A long history of recurrent pulmonary infection and signs of pulmonary hypertension and cyanosis may suggest a diagnosis of chronic pulmonary heart disease but, as pointed out by Platts and Whitaker (1954), the absence of carbon-dioxide retention will exclude this.

The degree of polycythæmia may be so extreme as to mimic polycythæmia rubra vera but this can usually be excluded by the normal hæmatological findings in other than the red cell series and by complete cardiological examination.

The frequency of a mitral diastolic murmur with this anomaly causes it to be confused with mitral stenosis and pulmonary hypertension and it may be impossible to distinguish this without special investigation. The differentiation may only be made when an angiocardiogram shows simultaneous filling of the pulmonary arteries and descending aorta, when a catheter passes through a patent ductus, or when an increase in blood oxygen saturation is demonstrated in the pulmonary arteries.

Patients with classical signs of an atrial septal defect can be differentiated from those with the present anomaly by the small pulse volume, a more marked cardiac enlargement, and marked pulsation in the pulmonary arteries amounting to a hilar dance. Others with less typical clinical and radiological signs may only be recognized by demonstrating a left-to-right shunt in the atria in acyanotic patients or by passing a catheter through the atrial septal defect. Angiocardiographic examination will differentiate patients with atrial septal defect and reversal of flow by demonstrating early filling of the left atrium. A right bundle branch block pattern in the electrocardiogram will not differentiate the two conditions since this occurs with both.

Since the clinical, radiological, and electrocardiographic features of ventricular septal defect and Eisenmenger's complex may be indistinguishable from the present anomaly, these lesions are difficult to differentiate from it. An increase in blood oxygen saturation in the right ventricle 
does not always indicate a ventricular septal defect since it may be the result of pulmonary incompetence associated with patent ductus arteriosus and pulmonary hypertension. However, as it is usually easy to pass a catheter through a patent ductus arteriosus when there is associated pulmonary hypertension, failure to carry out this manœuvre, where there is increased blood oxygen saturation in the right ventricle, suggests that the patient has a ventricular septal defect and not a patent ductus arteriosus with severe pulmonary hypertension. The problem of differentiating the present anomaly from a ventricular septal defect with pulmonary hypertension and from Eisenmenger's complex is made even more difficult by the fact that these lesions may co-exist, as in Cases 2 and 3.

Eisenmenger's complex will be diagnosed in a patient with pulmonary hypertension when, on angiocardiographic examination, there is simultaneous and early filling of the ascending aorta and pulmonary artery from the right ventricle but, even when this occurs, cardiac catheterization may subsequently demonstrate a patent ductus arteriosus, as in Case 2 in the present series. In such a patient, the possibility that the ascending aorta is filled by regurgitation of blood entering the aorta by a patent ductus arteriosus cannot be completely dismissed but such an explanation seems unlikely when there is a large amount of contrast medium in the ascending aorta (Fig. 6).

As many of the patients with the present anomaly present only symptoms and signs of pulmonary hypertension it seems probable that many so-called cases of idiopathic pulmonary hypertension are, in fact, examples of the present congenital lesion. During the time that we have seen these eight patients, we have seen no case of idiopathic pulmonary hypertension and this diagnosis is one which should only be made when autopsy proof is available.

Patients with Fallot's tetralogy with loud and even palpable sounds in the pulmonary area may be considered on clinical examination to have cyanotic congenital heart disease and pulmonary hypertension and, possibly, patent ductus arteriosus and pulmonary hypertension. Such patients are, however, easily differentiated by measurement of pulmonary artery blood pressures.

\section{TREATMENT}

There is not yet sufficient evidence available to allow dogmatic statements to be made about the place of surgical treatment in cases of patent ductus arteriosus complicated by pulmonary hypertension. Dammann and Sell (1952) feel that the presence of pulmonary hypertension is an added indication for surgical treatment of the patent ductus arteriosus and point out that such treatment may be life saving. Hultgren et al. (1953) consider that surgery is indicated when the shunt is dominantly left to right but feel that when reversal of the flow has occurred, ligation of the patent ductus arteriosus may be dangerous. In Cases 4 and 5 in the present series gross structural changes had occurred in the pulmonary arteries, suggesting that the pulmonary hypertension was irreversible and that surgery was contra-indicated. It seems probable that patients with generalized cyanosis, where the shunt is dominantly from the pulmonary artery to the aorta, will be unsuitable for any surgical treatment. It is important in other patients to assess the individual at the time of operation from recording the pulmonary arterial blood pressure. This also seems to be Brock's view, since Braun et al. (1954) reporting a patient treated surgically by him, state that he believes that, if after digital compression of the patent ductus arteriosus the pulmonary artery pressure drops, the ductus can be ligated with safety, but, if the pressure rises, closure of the abnormal communication may be dangerous.

\section{SUMMARY}

Eight patients with patent ductus arteriosus and severe pulmonary hypertension are described and an account of the autopsy findings in two of these is given.

The features of this anomaly are sufficiently clearly defined for it to be regarded as a specific entity. Breathlessness on exertion, hæmoptysis, cyanosis, and recurrent chest infections were the common symptoms. 
On physical examination, the most characteristic signs were those of pulmonary hypertension which was the only clinical diagnosis that could be made consistently in the present series.

Six of the eight patients were cyanosed and in two of these this was more marked in the lower extremities. Although cyanosis may or may not occur, it is of great diagnostic importance when confined to the lower extremities, since this sign is specifically one of patent ductus arteriosus with pulmonary hypertension, but may be exaggerated if there is associated coarctation of the aorta.

With the exception of a Gibson murmur, which is rare, basal murmurs are of little diagnostic importance in this anomaly since it may present with only a systolic murmur or only a diastolic murmur, a systolic murmur and diastolic murmur, or no murmurs.

All eight patients had electrocardiographic evidence of right ventricular preponderance and two had, in addition, a right bundle branch block pattern.

Radiologically, all the patients had cardiac enlargement, mainly due to right ventricular hypertrophy, and increased prominence of the pulmonary artery and its branches, with abnormal pulsation not amounting to hilar dance.

Angiocardiography showed early filling of the descending aorta from the pulmonary artery in five cases.

In five of the six patients investigated by cardiac catheterization the catheter passed through the patent ductus arteriosus into the descending aorta indicating that this manœuvre is of the greatest importance in diagnosis. Eisenmenger's complex, atrial or ventricular defects with pulmonary hypertension, and mitral stenosis with pulmonary hypertension may all appear indistinguishable from the present anomaly on clinical, cardiographic, and radiological examination and may be differentiated only by angiocardiography and cardiac catheterization.

At autopsy the patent ductus was abnormally large in both cases. On histological examination the pulmonary arteries showed changes typical of those found in patients with congenital heart disease and pulmonary hypertension. One case had medio-necrosis of the main pulmonary artery and aorta.

Surgical treatment is contra-indicated in patients with generalized cyanosis. In other cases treatment will depend on the assessment of the patient at the time of operation.

We are grateful to Dr. C. E. Davies and Professor C. H. Stuart-Harris for allowing us to report Cases 4 and 5 who were seen in the wards of the Professorial Unit of the Royal Hospital, Sheffield, and to Dr. J. L. Edwards for allowing us access to the pathological material in these cases. We would like to thank Miss E. K. Abbott, Consultant Radiologist, for facilities in the Radiological Department, City General Hospital, Sheffield, and Mr. Nichols and Miss N. Hardy for technical assistance. We also wish to thank Mr. A. S. Foster, Artist to the United Sheffield Hospitals, and Mrs. Rose of the Photographic Department of the Royal Hospital, Sheffield.

\section{REFERENCES}

Bothwell, T. H., Van Lingen, B., Whidborne, J., Kaye, J., McGregor, M., and Elliott, G. A. (1952). Amer. Heart J., 44, 360 .

Braun, K., Milwidsky, H., Izak, G., and Schar, S. (1954). Angiology, 5, 329.

Brown, J. W. (1950). Congenital Heart Disease. 2nd ed., Staples Press, London.

Burchell, H., Swan, H. J. C., and Wood, E. H. (1953). Circulation, 8, 681.

Campbell, M., and Hudson, R. (1951). Guy's Hosp. Rep., 100, 26.

Cosh, J. (1953). Brit. Heart J., 15, 423.

Dammann, J. F. Jr., and Sell, C. G. R. (1952). Circulation, 6, 110.

Denolin, H., Lequime, J., and Segers, M. (1952). Cardiologia, 21, Fasc. 1.

Hultgren, H., Selzer, A., Purdy, A., Holman, E., and Gerbode, F. (1953). Circulation, 8, 15.

Johnson, R. E., Wermer, P., Kuschner, M., and Cournand, A. (1950). Circulation, 1, 1293.

Platts, M. M., and Whitaker, W. (1954). Amer. Heart J., 48, 77.

Smith, G. (1954). Brit. Heart J., 16, 233. 